\title{
1 Use of structured decision-making to explicitly incorporate 2 environmental process understanding in management of 3 coastal restoration projects: case study on barrier islands of 4 the northern Gulf of Mexico
}

5 P. Soupy Dalyander ${ }^{\mathrm{a}^{*}}$, Michelle Meyers $^{\mathrm{b}}$, Brady Mattsson $^{\mathrm{c}}$, Gregory Steyer $^{\mathrm{d}}$, Elizabeth Godsey ${ }^{\mathrm{e}}$,

6 Justin McDonald $^{\mathrm{e}}$, Mark Byrnes ${ }^{\mathrm{f}}$, Mark Ford ${ }^{\mathrm{g}}$

7 *Corresponding Author.

$8 \quad{ }^{\text {a }}$ U.S. Geological Survey, St. Petersburg Coastal and Marine Science Center, $6004^{\text {th }}$ Street S, St.

9 Petersburg, FL, USA. sdalyander@usgs.gov

10 bU.S. Geological Survey, National Wetlands Research Center, 700 Cajundome Blvd, Lafayette,

11 LA, USA. mmeyers@usgs.gov

$12{ }^{\text {C}}$ University of Natural Resources and Life Sciences Vienna, Gregor-Mendel-Straße 33, 1180

13 Vienna, Austria. brady.mattsson@boku.ac.at

14 dU.S. Geological Survey, c/o Livestock Show Office, Louisiana State University, Baton Rouge,

15 LA, USA. gsteyer@usgs.gov

16 e U.S. Army Corps of Engineers, Mobile District, 109 St. Joseph Street, Mobile, AL, USA.

17 Elizabeth.S.Godsey@usace.army.mil; Justin.S.McDonald@usace.army.mil

$18{ }^{\mathrm{f}}$ Applied Coastal Research and Engineering, 766 Falmouth Rd., Suite A-1 Mashpee, MA, USA.

19 mbyrnes@appliedcoastal.com

$20{ }^{\mathrm{g}}$ National Park Service, Southeast Regional Office, New Orleans, LA, USA.

21 mark_ford@nps.gov 


\section{Abstract}

2 Coastal ecosystem management typically relies on subjective interpretation of scientific

3 understanding, with limited methods for explicitly incorporating process knowledge into decisions that must meet multiple, potentially competing stakeholder objectives. Conversely, the scientific community lacks methods for identifying which advancements in system understanding would have the highest value to decision-makers. A case in point is barrier island restoration, where decision-makers lack tools to objectively use system understanding to determine how to optimally use limited contingency funds when project construction in this dynamic environment does not proceed as expected. In this study, collaborative structured decision-making (SDM) was evaluated as an approach to incorporate process understanding into mid-construction decisions and to identify priority gaps in knowledge from a management perspective. The focus was a barrier island restoration project at Ship Island, Mississippi, where sand will be used to close an extensive breach that currently divides the island. SDM was used to estimate damage that may occur during construction, and guide repair decisions within the confines of limited availability of sand and funding to minimize adverse impacts to project objectives. Sand was identified as more limiting than funds, and unrepaired major breaching would negatively impact objectives. Repairing minor damage immediately was determined to be generally more cost effective (depending on the longshore extent) than risking more damage to a weakened project. Key gaps in process-understanding relative to project management were identified as the relationship of island width to breach formation; the amounts of sand lost during breaching, lowering, or narrowing of the berm; the potential for minor breaches to self-heal versus developing into a major breach; and the relationship between upstream nourishment and resiliency of the berm to storms. This application is a prototype for using structured decisionmaking in support of engineering projects in dynamic environments where mid-construction decisions may arise; highlights uncertainty about barrier island physical processes that limit the ability to make robust decisions; and demonstrates the potential for direct incorporation of process-based models in a formal adaptive management decision framework.

\section{Keywords}

Structured decision-making, ecosystem restoration, adaptive management, Mississippi Coastal Improvements Program, Gulf of Mexico, barrier islands

\section{Introduction}

Barrier islands are narrow island chains that run parallel to the mainland and protect it from wave attack. They also provide critical habitat for species such as sea turtles and shorebirds (Feagin et al., 2010). The cross-shore profile of a barrier island typically consists of a seaward facing lower 
typically dry but may be inundated during modest storm events; a dune that rises a few meters and is only reached by water levels during more extreme storms; and a back-barrier that may consist of lower beach habitat or marsh (Komar, 1988). The lower beach changes daily as a result of wave and tidal action, while the upper beach and dune regions evolve slowly under most conditions (Sallenger, 2000). During storms, however, elevated water levels can result in rapid changes to the upper beach and dunes (Sallenger et al., 2006; Stockdon et al., 2007). The cumulative impact of storms may result in longshore or cross-shore migration of the island while the subaerial profile is maintained (Morton et al. 2004). However, insufficient sediment supply, local sea level rise, anthropogenic modifications, and climatic changes in storm patterns can increase the vulnerability of barrier islands and raise the risk the islands (and their benefits) will be lost (Stutz and Pilkey, 2011). Threatened barrier islands may be targeted for restoration in order to preserve their natural and anthropogenic benefits.

13 The Mississippi barrier islands (Fig. 1) are the first line of defense between the Gulf of Mexico and the Mississippi mainland, and are an important habitat for threatened Gulf Sturgeon, endangered and threatened sea turtles species, and threatened shorebirds (USFWS, 2015). The islands are experiencing changes in subaerial acreage and habitat due to frequent intense storms, relative rise in sea level, and changes in sediment supply (Byrnes et al., 2013), similar to other islands in the northern Gulf of Mexico (Penland and Boyd, 1981; Morton, 2008; Otvos and Carter, 2008). Long-term island loss threatens the productive Mississippi Sound estuarine ecosystem and exposes the mainland coast and its wetland habitats to increasing saltwater intrusion and damage from tropical storms.

In 2009, the Mississippi Coastal Improvements Program (MsCIP) was developed by the Mobile District, U.S. Army Corps of Engineers (USACE) in conjunction with other Federal and State agencies. The Mississippi barrier island system was examined with the goal of restoring the natural ability of the barrier island system to reduce hurricane impacts (Wamsley et al., 2013). One planned coastal engineering project is the restoration of Ship Island. As of 1848 Ship Island was a single, low-elevation landform with intermittent marsh and areas of higher dunes at each end (Foxworth et al., 1962). Historical maps document breaching of the island after the "Great Mobile" hurricane of 1852 (Byrnes et al., 2012), but littoral sediment transport from eastern Ship Island supplied enough sand to close early breaches and maintain a continuous island. A breach created in the hurricane of 1947 remained open for many years, but closed at some point prior to Hurricane Camille in 1967 (Knowles and Rosati, 1989; Byrnes et al., 1991; Morton, 2007, 2008). Since the creation of Camille Cut, Ship Island has not reformed into a single island, despite some narrowing of the cut in the mid-1990s prior to Hurricane Georges (Byrnes et al., 2012). Multiple hurricanes in the years that followed (Georges, 1998; Ivan, 2004; Katrina, 2005) widened 
has undergone significant land loss, and between 1848-2008 lost more than 64\% of its area with an average loss of between 8.5-22.4 ha/yr between 1986-2005 (Morton, 2007, 2008).

3 The restoration project will close Camille Cut and restore sand to East Ship Island. Sand placed at the eastern end is expected to increase island resiliency by supplying sediment to areas to the west through the net westward longshore transport. In addition to sheltering the mainland, the project will restore subaerial habitat for shorebirds and sea turtle nesting. Due to the dynamic nature of barrier islands and the threat of extreme storms, portions of the project may be damaged during construction, forcing the project managers and engineers to make decisions regarding repairs. Damage and repair choices can potentially impact the resiliency of the completed project and thus its intended goals of mainland protection and habitat restoration, and must be made within the constraints of project resources.

Structured decision-making (SDM) can be used to arrive at a course of action when multiple, potentially conflicting objectives are present (Gregory et al., 2012; Runge et al., 2011a). The problem definition, objectives, potential actions, consequences, and tradeoffs of a decision are identified through a formal process known as PrOACT, which was developed using decision analysis theory to avoid psychological pitfalls that can inhibit individuals from making objective, value-focused decisions (Hammond et al., 1999; Runge et al., 2011a). The qualitative problemstructuring steps (problem definition, objectives, potential actions, and consequences) of PrOACT are particularly important to ensure that the decision-analytic framework is constructed in a way that fits to the real-world decision problem. SDM can be implemented in a collaborative decision analytic framework to increase transparency by actively engaging stakeholders (Thorne et al., 2015). SDM incorporates assumptions about how the system will respond, identifies sources of uncertainty, and estimates the value of reducing uncertainty through monitoring and research (Runge et al., 2011b). It can therefore serve as a framework for formal adaptive management, a strategy for monitoring a system after a management action is taken and using that knowledge to guide future actions (Walters, 1986; Nichols et al., 2011). SDM has been successfully applied for environmental planning, restoration, and adaptive management (e.g., Blomquist et al., 2010; Gregory and Long, 2009; Neckles et al., 2014; Runge et al., 2011b; Thorne et al., 2015). However, typical applications occur from the beginning of project planning, management actions are assumed to happen instantaneously, and adaptive management strategies are used when the system does not respond as expected to the completed project. The dynamic and uncertain nature of barrier islands combined with the phased nature of barrier island restoration projects make them ideal candidates for a novel mid-construction application of 34 SDM.

The focus of this study was to use SDM to develop a transparent framework informing choices 
and could ultimately impact project objectives. We also identified crucial uncertainties in

2 process-understanding that limit optimal management of barrier islands, and how the process might be improved in future applications and as part of regional-scale long-term adaptive resource management. This effort is the first that we are aware of to apply SDM to barrier island restoration or for mid-construction design decisions, and takes the novel step of directly incorporating observational data (in this case, storm inundation probabilities) into a decisionsupport framework. This project demonstrates that collaborative SDM can provide the backbone for formal adaptive management in dynamic and complex coastal environments, where decisions constrained by resources and potentially impacting competing project objectives may be required during and after restoration.

2. Background: Ship Island Restoration Project

12 The Ship Island restoration project was designed to be constructed over a period of $\sim 2.5$ years:

13 Phase B1, preliminary Camille Cut closure ( 15 months): During this phase, $\sim 6.0$ million 14 cubic yards (mcy) of medium sand $(0.30 \mathrm{~mm})$ would be used to close Camille Cut with a 15 subaerial berm of dimensions 5 feet (') high and 500' wide. An additional $~ 0.9$ mcy would extend the feature onto East Ship Island as a temporary sediment feeder to the new berm.

Phase B2, berm expansion ( 10 months): Immediately after completion of phase B1, 5.4 mcy of medium sand would increase the subaerial height to 7' and width to 1000'.

19 Phase B3, fine-grain sediment cap ( $\sim 5$ months): After phase B2, 1.1 mcy of fine sand (0.21 $\mathrm{mm}$ ) would be placed along the crest of the berm to serve as a foundation for dune vegetation.

Phase E, East Ship nourishment ( 7 months): Concurrent with phase B3, 5.5 mcy of medium sand would be added to the southern shoreline of East Ship Island and serve as a sediment source to the berm, extending and expanding the initial East Ship Island berm constructed in phase B1.

Phase V, dune vegetation planting ( $\sim 7$ months): The newly-created island segment would be planted with vegetation to restore stable dune habitat. Decisions related to this phase were not considered in the current effort.

27 The budget for Ship Island restoration at the time of the study was $\$ 382,200,000$, including a contingency budget of $32 \%(\$ 122,304,000)$ above anticipated costs. Preserving funds was not an explicit stakeholder goal; however, leftover funds could be used for other MsCIP projects. Up to 22 mcy of sand, the volume removed from Horn Island Pass during maintenance dredging between 1907 and 2005 (USACE, 2009) and assumed to be the amount loss from the system through longshore transport, could be placed at Ship Island. This volume included the anticipated 
construction volume of 17.9 mcy of medium material, 1.1 mcy of fine grain material, and up to 3 mcy of contingency sand to repair mid-construction damage.

3. Methods

\subsection{Decision Framework Structuring}

Two decision-analytic frameworks (DFs) were developed by a team that included the decisionmaker for the Ship Island project (lead MsCIP engineer with USACE); other stakeholders (USACE Operations Division engineer and a U.S. National Park Service ecologist); and technical experts in barrier island ecosystems. In a series of four webinars, a decision analyst described PrOACT and provided examples of past applications to familiarize the team with the approach. During each webinar, the analyst proposed and discussed the problem structuring (including objectives and alternatives) with the team. As such, team members had the opportunity to provide feedback on DF development and were engaged throughout the process. The analyst then led development of the initial DF during an in-person workshop, which further familiarized the team with PrOACT. During a subsequent workshop, the same approach was used to develop the second DF that explored the application of SDM to inform mid-construction decisions.

\subsubsection{Problem Definition}

For each DF, the decision analyst worked with the team to develop a question reflecting the key components of the decisions to be made. The first DF was based on the question, "How can MSCIP partners optimize decision making relative to Ship Island restoration and the benefits, including the use of monitoring and adaptive management practices during construction, given the uncertainties in budgets, storm impacts, and system response?", and focused on a choice of whether to repair a major breach in phase B2. For the second DF, the team refined the decision question to, "When should MSCIP partners repair weakening events (i.e., lowering or minor puncturing of the fill), if needed, within the Ship Island template to maximize the benefits, including the use of monitoring and adaptive management practices during construction, given the uncertainties in storm impacts and system response?", and the expanded DF considered repairing a wider range of possible damage.

\subsubsection{Objectives and Drivers}

Objectives for the project (Table 1) were refined from those established by the MSCIP Technical Advisory Group in the Supplementary Environmental Impact Statement (SEIS; USACE, 2009). Cost-savings was not a primary stakeholder goal, but the preference to preserve funds for other projects was accounted for by including cost-savings as an objective to quantify impacts of decisions on cost and vice-versa. It was assumed that regulations for threatened and endangered species would be met during project implementation, and they were not explicitly considered. 
1 Table 1. Ultimate objectives included in decision models providing management recommendations for the

2 restoration of Ship Island, Mississippi, USA. The seven original ultimate objectives were combined to five ultimate

3 objectives to avoid elicitation fatigue in the second decision model. "kcy" denotes 1000 cubic yards.

\begin{tabular}{|c|c|c|c|c|c|c|}
\hline \multirow[b]{2}{*}{$\begin{array}{c}\text { Ultimate } \\
\text { objective }^{\text {a }}\end{array}$} & \multirow[b]{2}{*}{$\begin{array}{c}\text { Component } \\
\text { objective }\end{array}$} & \multirow[b]{2}{*}{ Metric } & \multirow[b]{2}{*}{ Stakeholder concerns } & \multirow[b]{2}{*}{ Baseline } & \multicolumn{2}{|c|}{$\begin{array}{l}\text { Categories used for analysis } \\
\text { relative to baseline condition }\end{array}$} \\
\hline & & & & & Good outcome & Bad outcome \\
\hline \multirow{2}{*}{$\begin{array}{l}\text { Mississippi } \\
\text { sound } \\
\text { integrity }\end{array}$} & Salinity & $\begin{array}{l}\text { Salinity levels } \\
\text { in MS Sound }\end{array}$ & $\begin{array}{l}\text { Deviating from normal salinity } \\
\text { would negatively impact marine } \\
\text { species and communities }\end{array}$ & $\begin{array}{l}17-38 \\
\text { parts per } \\
\text { thousand }\end{array}$ & Within range & Outside range \\
\hline & $\begin{array}{l}\text { Sturgeon } \\
\text { habitat }\end{array}$ & $\begin{array}{l}\text { Acreage of } \\
\text { shallow habitat } \\
\text { near Ship } \\
\text { Island }\end{array}$ & $\begin{array}{l}\text { Loss of sturgeon habitat of any } \\
\text { amount relative to project- } \\
\text { completion acreage would } \\
\text { negatively impact the } \\
\text { population }\end{array}$ & $\begin{array}{c}0 \% \\
\text { habitat loss }\end{array}$ & Below & At or above \\
\hline \multirow{2}{*}{$\begin{array}{c}\text { Beach } \\
\text { habitat } \\
\text { integrity }\end{array}$} & $\begin{array}{l}\text { Shorebird } \\
\text { habitat }^{\mathrm{a}}\end{array}$ & $\begin{array}{l}\text { Acreage of } \\
\text { swash zone }^{c}\end{array}$ & $\begin{array}{l}\text { Loss of shorebird foraging } \\
\text { habitat at a rate greater than } \\
\text { expected following project } \\
\text { completion would negatively } \\
\text { impact their populations }\end{array}$ & $\begin{array}{c}23 \% \\
\text { habitat loss }\end{array}$ & Below & At or above \\
\hline & $\begin{array}{l}\text { Turtle- } \\
\text { nesting } \\
\text { habitat }\end{array}$ & $\begin{array}{l}\text { Acreage of } \\
\text { upper beach } \\
\text { habitat }^{\mathrm{d}}\end{array}$ & $\begin{array}{l}\text { Loss of turtle-nesting habitat at } \\
\text { a rate greater than expected } \\
\text { following project completion } \\
\text { would negatively impact their } \\
\text { populations }\end{array}$ & $\begin{array}{c}23 \% \\
\text { habitat loss }\end{array}$ & Below & At or above \\
\hline $\begin{array}{l}\text { Wave } \\
\text { attenuation }\end{array}$ & $\mathrm{n} / \mathrm{a}$ & $\begin{array}{l}\text { Difference in } \\
\text { wave height } \\
\text { between Gulf } \\
\& \text { MS Sound }\end{array}$ & $\begin{array}{l}\text { Decreased wave height } \\
\text { attenuation relative to project- } \\
\text { completion would endanger } \\
\text { communities along the } \\
\text { mainland coast }\end{array}$ & $\begin{array}{l}\text { As } \\
\text { measured at } \\
\text { project } \\
\text { completion }^{\mathrm{c}}\end{array}$ & At or above & Below \\
\hline $\begin{array}{l}\text { Gulfport } \\
\text { channel } \\
\text { shoaling }\end{array}$ & $\mathrm{n} / \mathrm{a}$ & $\begin{array}{l}\text { Shoaling rate } \\
\text { of Gulfport } \\
\text { navigation } \\
\text { channel }\end{array}$ & $\begin{array}{l}\text { Exceeding historic shoaling } \\
\text { rates }^{f} \text { would place economic } \\
\text { burden on dredging }\end{array}$ & $\begin{array}{c}250 \\
\mathrm{kcy} \mathrm{yr}^{-1}\end{array}$ & Below & At or above \\
\hline \multirow[t]{2}{*}{$\begin{array}{c}\text { Cost } \\
\text { savings } \mathrm{s}^{\mathrm{b}}\end{array}$} & $\mathrm{n} / \mathrm{a}$ & $\begin{array}{l}\text { Cost savings } \\
\text { for other } \\
\text { MsCIP } \\
\text { projects }\end{array}$ & $\begin{array}{l}\text { Having enough funds to conduct } \\
\text { high-priority MsCIP restoration } \\
\text { projects on the mainland coast } \\
\text { would be beneficial for those } \\
\text { communities }\end{array}$ & $\$ 39 M$ & At or above & Below \\
\hline & \multicolumn{6}{|c|}{ 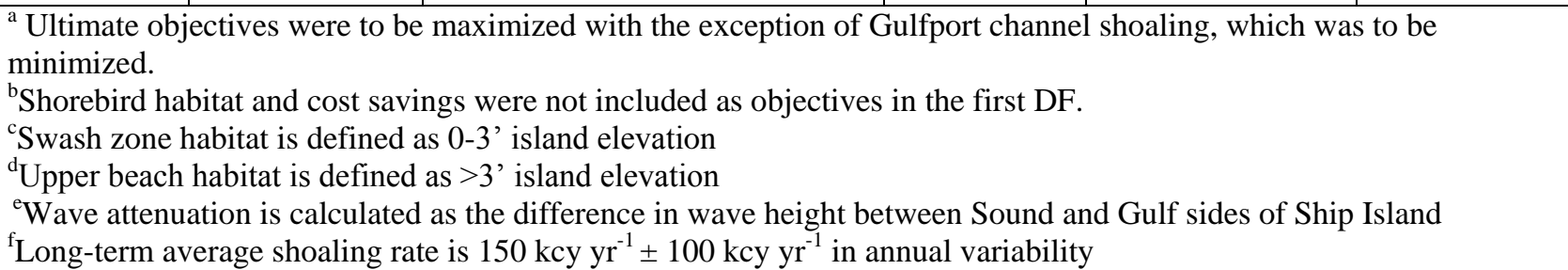 } \\
\hline
\end{tabular}


Storms were identified by technical experts as the dominant factor in project damage. Because storm damage to barrier islands has been correlated to water level relative to dune elevation (Sallenger, 2000), inundation was included as an external driver.

The design template accounted for an expected rate of erosion due to longshore transport, but the actual erosion rate could be greater due to higher-energy waves or unexpected variation in placed sediment grain size. In the first DF, longshore transport rate was included as an external driver and a management action of offsetting a greater-than-expected rate with additional sand placement at East Ship was considered. The technical experts later determined it would be impossible to robustly quantify the longshore transport rate at the point of the decision, so it was excluded from the second DF and results are not presented here.

\subsubsection{Potential Damage and Alternative Strategies}

Water reaching the base of the berm may narrow it through erosion, while the berm may be lowered in height or breached (removal of sand to the base) if water reaches the top of the berm through wave runup (overwash) or storm surge and tides (inundation). The cross-shore width of a berm or dune field is also expected to influence storm response (e.g., Claudino-Sales, 2008; Houser et al., 2008; Plant and Stockdon, 2012), but this dependence is less quantified.

The technical experts on the team identified the following potential:

1. Major breach. A major breach was defined as a large loss of sediment and significant reopening of the cut in the island that is being closed to meet project objectives.

2. Minor damages. Less severe damage may directly (through habitat destruction or the cost to repair) or indirectly (by making the project more susceptible to future, major damage) impact objectives. Minor damages included:

a. Moderate or minor breach in berm. Smaller breaches can widen during future storm events, such as previously occurred with Camille Cut.

b. Berm lowering. Because the likelihood of breaching depends on berm height relative to water level, lowering of berm or dune elevation during overwash and inundation events increases vulnerability to future breaching.

c. Berm narrowing. During more moderate storms, narrowing would likely occur along portions of the berm.

d. Loss of East Ship Island sand. The sand placed on East Ship Island creates local habitat and is a sand feeder to help maintain the beach to the west. If this area is inundated and sand is lost, both of those functions might be impaired.

The first DF focused on whether to repair a major breach that occurred after the berm was expanded in phase B2. This decision was a simple yes/no, with no alternatives. 
The second DF considered repair of minor damages. Damages incurred in phases B1 and B2 could be repaired immediately by backtracking sand placement equipment, or they could be repaired during subsequent phases B2 and B3, respectively, as part of scheduled sand placement. Because phases B2 and B3 place sand atop the berm constructed in phases B1 and B2, respectively, there is not a 'no repair' option for phases B1 and B2. Immediate repairs incur remobilization cost, while leaving the berm weakened until the next phase raises the risk of additional damage and need for even more sand. For damage in phase B3, there was a choice to repair or not, and an additional choice to use fine or medium sand. The fine-grain sand is easier to transport during a storm (Soulsby, 1997; USACE, 2009), therefore its use would potentially

10 decrease berm resiliency. However, the dredging site for fine-grain material is within Mississippi 11 waters and, as a result, costs less than medium sand that must be attained elsewhere.

\subsubsection{Consequences}

In the first DF, the continued presence of a major breach could impact all objectives (Fig. 2). The possibility that insufficient funds would remain to repair a breach in the expanded berm if funds had previously been expended to repair a prior major breach in phase B1 was considered.

The second DF included a sequence of decisions about repairing damages to the berm in each phase (influence diagram shown in two parts in Fig. 3 and Fig. 4). For phases B1-B3, the condition of the berm at the end of the phase depends on the occurrence (due to storms or unrepaired damage in prior phases) and possible repair (at a sand and money cost) of narrowing, lowering, or breaching. The final berm condition determines the likelihood of a major breach post-construction (defined as the 10-year period after project completion), which influences all of the non-cost objectives. For phase E, the final elevation of East Ship Island determines its suitability as sea turtle nesting habitat and is a function of storm-induced lowering. The technical experts agreed that sand placed at East Ship Island would nourish the berm and increase resiliency; however, the level of uncertainty in quantifying that relationship was so high that phase $\mathrm{E}$ was not linked to potential for berm breaching. Linkages between ultimate and component objectives (Table 1) were established via technical expert elicitation (e.g., experts indicated the probability that Mississippi sound integrity would decrease as a function of sturgeon habitat loss and salinity changes).

\subsubsection{Tradeoffs and Optimization}

31 Related objectives were combined in the second DF to reduce the set of unique outcome scenarios that decision makers had to rank to five: avoiding degradation of MS Sound ecological integrity; not increasing shoaling into the Gulfport navigation channel; protecting the mainland

34 through wave attenuation; preserving the ecological integrity of beach habitat; and cost savings

35 (Table 1). Stakeholders independently quantified their level of satisfaction with possible combinations of objective outcomes so that tradeoffs could be evaluated (see section 3.2.3). 
$1 \quad 3.2$ Model Parameterization and Analysis

2 DFs were developed from influence diagrams as Bayesian networks with three types of nodes:

3 decision nodes representing management options; stochastic (i.e., probabilistic) nodes

4 representing drivers and objectives; and utility nodes representing tradeoffs among objectives.

$5 \quad$ 3.2.1 Assigning Probability Distributions

6 Historical water level distributions (USACE, 2009) were used to quantify the cumulative

7 probability that the berm would be inundated during each phase and in the 10 years post-

8 construction. The probability distributions for the rest of the stochastic nodes were extracted

9 through expert elicitation following a Delphi Method (Dalkey, 1969; Kuhnert et al., 2010) with

10 one round of revisions. Technical experts self-determined if they were qualified to respond to

11 each question, and gave initial probabilities anonymously (Table 2). The decision analyst shared

12 summary statistics such as the average response value, and also identified logical inconsistencies

13 based on group discussion (e.g., risk of breaching must increase with inundation). Experts were

14 given an opportunity to revise their answer, which was done in some cases. Group consensus

15 regarding the averaged probability distributions for the decision analysis was reached during

16 webinars with the team. Additional details on this process may be found in Appendix 1 of

17 Thorne et al. (2015).

\subsubsection{Estimating Sand Loss Volumes and Associated Costs}

All sand loss thresholds were identified via group consensus. For the first DF, a major breach in

the final berm template was defined as $>1$ mile of longshore sand loss corresponding to $>1 \mathrm{mcy}$ sand loss. This benchmark was based on the 2005-2006 breach that occurred at Dauphin Island during Hurricane Katrina (estimated as a 500 year occurrence; Wamsley et al., 2013). For the second DF, a major breach was defined as a loss of $>670$ cubic yards $x 10^{3}(\mathrm{kcy})$ of sand (equivalent of 1500' longshore length), corresponding to the long-term average breach length.

Additional thresholds were established for the second DF: breaching in the initial berm closure was defined as $>90 \mathrm{kcy}$ (500' of longshore length) of sand lost; moderate breaching of the final berm template was defined as 220-670 kcy (500'-1500' of longshore length) of sand lost; and breaching below these thresholds was considered as lowering of the berm to less than 3 ' in 29 elevation. 
1 Table 2. Expert elicited volumes and dimensions of sand loss from minor damage to the Camille Cut berm.

2 Dimensions were averaged across independently elicited expert values. Volumes are calculated from dimensions of 3 sand loss (Fig. 5). "DF" stands for "decision framework".

\begin{tabular}{|c|c|c|c|c|}
\hline Damage type & Volume lost (kcy) & $\begin{array}{l}\text { Longshore length } \\
\text { affected (') }\end{array}$ & $\begin{array}{l}\text { Cross-shore } \\
\text { width lost (') }\end{array}$ & $\begin{array}{l}\text { Height lost } \\
\left(^{\prime}\right)^{\mathrm{a}}\end{array}$ \\
\hline \multicolumn{5}{|c|}{ Preliminary Camille Cut Closure (5' high, 500' wide) ${ }^{\mathrm{b}}$} \\
\hline Breach $(>90$ kcy) & 302 & 1633 & 500 & $5+5$ \\
\hline \multicolumn{5}{|l|}{ Lowering } \\
\hline to 4' above sea level & 40 & 2167 & 500 & 1 \\
\hline to $\leq 3$ ' above sea level & 113 & 1750 & 500 & 3.5 \\
\hline \multicolumn{5}{|l|}{ Narrowing } \\
\hline to $351-499$ ' wide & 97 & 7000 & 74.5 & 5 \\
\hline to $201-350$ ' wide & 78 & 1867 & 224.5 & 5 \\
\hline to $1-200$ ' wide & 148 & 2000 & 400 & 5 \\
\hline \multicolumn{5}{|c|}{ Full Berm Template (7’ high, 1000' wide) } \\
\hline \multicolumn{5}{|l|}{ Breaching } \\
\hline Major breach, first $\mathrm{DF}^{\mathrm{d}}$ & $>1000$ & $>5280$ & 1000 & $7+5$ \\
\hline $\begin{array}{l}\text { Major breach }(>670 \mathrm{kcy}) \text {, } \\
\text { second DF }\end{array}$ & 889 & 2000 & 1000 & $7+5$ \\
\hline $\begin{array}{l}\text { Moderate breach (220-670 } \\
\text { kcy), second DF }\end{array}$ & 556 & 1250 & 1000 & $7+6$ \\
\hline \multicolumn{5}{|l|}{ Lowering ${ }^{e}$} \\
\hline to 6' above sea level & 204 & 5500 & 1000 & 1 \\
\hline to 5' above sea level & 204 & 2750 & 1000 & 2 \\
\hline to 4' above sea level & 306 & 2750 & 1000 & 3 \\
\hline to $\leq 3$ ' above sea level & 530 & 2600 & 1000 & 5.5 \\
\hline \multicolumn{5}{|l|}{ Narrowing } \\
\hline to 501-699' wide ${ }^{\text {f }}$ & 595 & 5100 & 450 & 7 \\
\hline to $351-500$ ' wide & 410 & 2750 & 574.5 & 7 \\
\hline to 201-350' wide & 517 & 2750 & 724.5 & 7 \\
\hline to $1-200$ ' wide & 700 & 3000 & 900 & 7 \\
\hline \multicolumn{5}{|c|}{ East Ship Island sand placement } \\
\hline $\begin{array}{l}\text { Lowering to } \leq 3 \text { ' above sea level } \\
\text { across } \geq 50 \% \text { surface area }\end{array}$ & 528 & 5280 & 102 & $\geq 3$ \\
\hline
\end{tabular}


${ }^{a}$ Height of sand loss is given as height from top of berm to sea level + channel depth (for breach)

${ }^{\mathrm{b}}$ These dimensions apply to phase B1 after completion and phase B2 ahead of construction

${ }^{c}$ These dimensions apply to phase B2 after completion, phase B3, and post-construction

In the first DF, breach sand loss was not accounted for explicitly and therefore did not require a specific volume.

Breach volumes for the second DF are averaged over expert responses.

'Minor breaching less of less than $220 \mathrm{kcy}$ is considered lowering to $\leq 3$ ' above sea level

'Project design is based on an expectation of narrowing down to a minimum of 700 ', therefore a width greater than

this threshold does not require repair

2 For minor damage to the berm technical experts independently provided estimates of the 3 minimum, expected, and maximum longshore length of the berm impacted for each type of 4 minor damage (see Supplementary Material, Table S1). A simplified estimate of the as-built 5 berm geometry was used to calculate how much sand would be required for repairs from elicited 6 values of longshore length impacted (Fig. 5). Experts were provided with data derived from 7 satellite imagery on the occurrence and widths of breach and island sand loss for Ship and Horn 8 Islands over the period of 1984-2014 to aid them in their responses. If averaged elicited sand 9 volumes for lowering fell below the previously mentioned breach sand volumes, the breach 10 volume was used instead. At East Ship, the experts estimated the probability that greater than $1150 \%$ of the added fill would be lowered from 6' to 3', and then provided estimates of the 12 minimum, expected, and maximum volume of sand that would be lost were that to occur. The 13 second DF resolved time by construction phase due to limits on computational expense. At each

14 time step, the sand needed for that phase (design plus repairs) was subtracted from the total available. Repairs done "immediately" occurred within the DF at the end of each phase.

16 Monetary expenditures were calculated by converting the sand volume at a rate of $\$ 20$ per cubic yard. To

17 put cost-savings in context, the decision-maker identified high priority MsCIP projects that could

18 be enabled with leftover contingency funds from Ship. The total cost of these projects was \$39

19 million (M), which was used as the threshold for a positive cost-savings outcome. Repairs

20 delayed to a future phase include the sand volume used to repair and a probable sand loss from

21 bigger breaching in the subsequent phase, calculated from the elicited likelihood of major

22 damage prior to repair and the associated sand lost. Immediate repairs include the same components as well as an equipment remobilization cost estimated as $\$ 108$ thousand $(\mathrm{K})$.

24 To avoid elicitation fatigue, berm width and height were discretized to as few states as possible. Experts provided probabilities for post-damage berm state (benchmarked as the minimum height or width in the longshore) as a function of all possible combinations of pre-existing damage and water level ranges (Supplementary Material Table S2). Values for phase B3 and postconstructions were auto-filled when possible from the expert's prior responses for phase B2. 
because the physical state of the berm if no damage occurred (or if all damage was repaired) was identical in phase B3 and post-construction to the state at the end of phase B2.

\subsubsection{Quantifying Stakeholder Satisfaction and Expected Performance}

Each stakeholder independently quantified their anticipated satisfaction (formally, utility values; Thorne et al. 2015) with every possible combination of outcomes for the binary ultimate objectives as a score ranging from 0 (totally dissatisfied) to 100 (full satisfied). Satisfaction scores were elicited via the Delphi Method with one round of revisions, during which none of the stakeholders changed their scores. Perceived tradeoffs and synergies between the objectives were thus reflected through the elicitation of satisfaction scores. Group consensus regarding the averaged utility values for the decision analysis was reached during webinars with the team.

11 Satisfaction scores and probability distributions for the stochastic nodes were used to calculate expected performance (also known as expected utility) for each repair option as the percent likelihood of a good outcome across all the ultimate objectives (see Thorne et al., 2015). When expected performances were nearly identical between repair options, extreme values from the technical experts (e.g., the maximum sand loss) were used to examine the impact of uncertainty.

4. Results

\subsection{Sand and Money as Limiting Resources}

The values of sand loss varied depending with the type of damage (Table 2). There was a wide range of values given between the minimum, expected, and maximum sand loss, averaged across the technical experts (Fig. 6). On average, experts indicated less extreme lowering or narrowing would impact a wider longshore section of the berm than more significant damage.

Development of the first DF revealed that sand was more limited than funds. The cost of the 3 mcy of sand that could be placed for repairs is $\$ 60 \mathrm{M}$, well below the $\$ 122 \mathrm{M}$ contingency budget. Similarly, there would be enough funds to place the maximum allowed amount of sand for minor repairs even if remobilization costs of $\$ 108 \mathrm{~K}$ were incurred in each phase, and so budget was not a constraint. The second DF, therefore, informs managers on what scenarios might result in a sand shortage, and if sufficient funding would remain for other priority projects.

\section{8}

\subsection{Repairing a Major Breach in the Camille Cut Berm}

Repairing a 500-year breach had a higher expected performance (83\%) than not repairing (68\%) (results from first DF). Under the repair option, there was a 50\% greater chance of increased wave attenuation and a 5\% lower chance of abnormal salinity, with a negligible effect on the other objectives (Fig. 7A). Based on feedback from the technical experts, this low impact is a result of several factors. In the case of turtle nesting habitat, the creation of additional habitat at 
1 East Ship lowers the odds that the benchmark of a $23 \%$ of habitat loss would be met. For

2 sturgeon habitat, experts indicated it was not clear whether a breach would increase or decrease

3 their habitat, and similarly it was not apparent whether shoaling into the Gulfport channel would

4 increase (due to potential for sediment from the berm to be introduced to the longshore transport system) or decrease (due to a breach interrupting longshore transport).

A major post-construction breach would impact wave attenuation, turtle nesting habitat, and shorebird habitat, while having small impacts on other objectives (second DF; Fig. 7B). These results present the impacts of a major breach post-construction, as opposed to an unrepaired breach during construction as was explored in the first DF (Fig. 7A). However, the 20\% reduction between the first and second DF in probability of good outcome for turtle nesting habitat also results from changes in elicited values from the technical experts.

\subsection{Repairing Minor Damages to the Camille Cut Berm}

The difference in expected cost and probability of a major breach occurring prior to the next phase for phases B1 and B2 varies depending on the type and extent of minor damage (Table 3). Expected costs for immediate repairs of more extensive minor damages are lower for immediate repair due to the greater probability of future damage, whereas the increased risk of future major damage does not offset the backtracking cost for less extensive damage.

If extensive minor damages (narrowed to 1-200' longshore width, lowered to <4' height; Table 3) occur during phase B3 and repairing these damages would exceed the cost-savings threshold of $\$ 39 \mathrm{M}$, then the expected performances of the repair options $(79 \%$ and $80 \%$ for fine sand and medium sand, respectively) were 1-2\% less than that of not doing repairs (81\%). If less-extensive damages (narrowed to 351-500' longshore width, lowered to 6' elevation) occur during phase B3 and repairing these damages would exceed the cost-savings threshold, then the expected performance of repairing $(80 \%)$ was $7 \%$ less than that of not repairing $(87 \%)$. The difference between using medium or fine sand was negligible. The probability of a good outcome for each ultimate objective improved by $<3 \%$ with repairing less-extensive minor damage (Fig. 8).

Repairs had a low influence on expected performance despite the influence of a major breach on objectives (Fig. 7). This result was explored by considering individual components contributing to the risk of post-construction breaching. For berm heights greater than 5', the probability of an inundation event in the 10 years post-construction is relatively low (10-30\%; Fig. 6C). Technical experts indicated a low probability of breaching without inundation (e.g., Fig. 6D), so the likelihood of a major breach occurring is low whether minor damages are repaired or not. This low probability of a major breach reduces the impact of the minor damage repair decision on the 
weighting. If it is assumed that an inundation event will occur, the likelihood of a major breach

2 occurring post-construction increases considerably (Fig. 6D).

3 Table 3. Difference in expected sand loss, cost, and probability of a bigger breach that results from waiting to repair 4 minor damages to Camille Cut berm versus repairing immediately. Positive values indicate the value is higher for 5 waiting. Narrowing to 1-200' during phase B1 would trigger automatic immediate repair ("n/a").

\begin{tabular}{|c|c|c|c|}
\hline \multirow[b]{2}{*}{ Damage } & \multicolumn{3}{|c|}{$\begin{array}{l}\text { Difference Between Repairing Minor Damages During the } \\
\text { Subsequence Phase and Repairing Immediately }\end{array}$} \\
\hline & $\begin{array}{l}\text { Expected Sand } \\
\operatorname{loss}^{\mathrm{a}}(\mathrm{kcy})\end{array}$ & $\begin{array}{c}\text { Expected Cost } \\
(\$ K)\end{array}$ & $\begin{array}{c}\text { Probability of a Major } \\
\text { Breach }^{c}(\%)\end{array}$ \\
\hline \multicolumn{4}{|l|}{ Phase B1 ${ }^{d}$} \\
\hline \multicolumn{4}{|l|}{ Lowering } \\
\hline to 4' above sea level & 10.7 & 214 & 17.6 \\
\hline to $\leq 3$ ' above sea level & 23.5 & 470 & 31.7 \\
\hline \multicolumn{4}{|l|}{ Narrowing } \\
\hline to $351-499^{\prime}$ wide & -5.4 & -108 & 0.00 \\
\hline to $201-350$ ' wide & 3.8 & 76 & 10.0 \\
\hline to $1-200$ ' wide & $\mathrm{n} / \mathrm{a}$ & $\mathrm{n} / \mathrm{a}$ & $\mathrm{n} / \mathrm{a}$ \\
\hline
\end{tabular}

\section{Phase B2 ${ }^{e}$}

\begin{tabular}{|c|c|c|c|}
\hline \multicolumn{4}{|l|}{ Lowering } \\
\hline to 6' above sea level & -3.8 & -76 & 0.27 \\
\hline to 5' above sea level & -2.1 & -42 & 0.61 \\
\hline to 4' above sea level & 6.1 & 122 & 2.09 \\
\hline to $\leq 3^{\prime}$ above sea level & 12.6 & 252 & 3.26 \\
\hline \multicolumn{4}{|l|}{ Narrowing } \\
\hline to 501-699' wide & -5.4 & -108 & 0.00 \\
\hline to $351-500$ ' wide & 1.9 & 37 & 0.84 \\
\hline to $201-350$ ' wide & 13.7 & 274 & 2.24 \\
\hline to $1-200^{\prime}$ wide & 46.7 & 934 & 5.01 \\
\hline
\end{tabular}

${ }^{a}$ Expected sand loss is calculated from the probability of a major breach and the sand loss associated with it ${ }^{b}$ Expected cost is calculated from the expected sand loss, and for immediate repairs also includes the backtracking cost

${ }^{c}$ Probability of a major breach occurring ahead of construction during the subsequent phase

'If minor damage is repaired immediately during phase B1, the probability of a major breach ahead of construction in phase B2 is $16.2 \%$, with an expected sand loss of $20.1 \mathrm{kcy}$ and cost of $\$ 402 \mathrm{~K}$

${ }^{\mathrm{e}}$ If minor damage is repaired immediately during phase B2, the probability of a major breach ahead of construction in phase B3 is $0.4 \%$, with an expected sand loss of $7.9 \mathrm{kcy}$ and cost of $\$ 158 \mathrm{~K}$ 
1 We also evaluated how the expected performance changed within the range of elicited values.

2 Using the highest probability of effectiveness for medium sand and the lowest probability of

3 effectiveness with no repair, the repair option had 30\% greater expected performance (83\%) than

4 the no-repair option (53\%) for extensive minor damages. Four of the objectives (shorebird

5 habitat, sea-turtle nesting habitat, ecological integrity of the Ship Island beach, and wave

6 attenuation) were $>5 \%$ more likely to have a good outcome under the repair options than under

7 the no-repair option (Fig. 8). This change in the expected performance between sets of inputs

8 indicates a high level of uncertainty as quantified by the range in expert-estimated values.

\section{$9 \quad$ 4.4 Repairing Minor Damage at East Ship Island}

10 Under a worse-case scenario for sand loss and replacement (i.e., extensive minor damages and

11 bigger breaching) in phases B1 through B3, the expected amount of sand used based on averaged

12 expert inputs ( $23.0 \mathrm{mcy}$ ) is above the limit of $22 \mathrm{mcy}$. Under this highly unlikely scenario

13 (probability 2.7e-26), there would be insufficient sand to complete phase B3 and construct the

14 template for East Ship Island (phase E). Because of this small probability, we assumed there

15 would be enough sand to complete phase B3, but allowed the possibility of insufficient sand for

16 phase E. If sand placed in phase $E$ is lowered to a height of 3' or less over at least half of its

17 surface area and the cost-savings threshold of \$39M has not yet been exceeded, expected

18 performance was $8 \%$ greater if this damage is repaired (81\% expected performance) than not

19 (73\% expected performance). This improvement resulted from the relationship between East

20 Ship Island and sea-turtle nesting habitat: there is a 5\% greater chance of a good outcome (i.e., if

21 the lowered sections are repaired.

5. Discussion

The Ship Island decision frameworks (DFs) demonstrate how collaborative SDM can inform mid-construction decisions in dynamic environments such as barrier islands, where the system may evolve rapidly during project execution. In essence, the Bayesian network created with Netica $\odot$ forms a decision support system for the project. The need for this planning support was highlighted during development of the first DF. Because non-financial objectives are related to island integrity, improved expected performance from repairing a major breach is intuitive. However, there was much more uncertainty about the impacts other damage and repair decisions made within the context of limited resources (sand, funds) would have on resiliency. In the following sections, we describe some of the challenges and potential improvements for future applications, such as research in barrier island physical processes that could substantially reduce decision uncertainty and considerations for DF implementation and interpretation of results. We then describe how the framework developed here could be expanded for longer-term and/or 
$1 \quad 5.1$ Mid-Construction Decision Framework for Dynamic Environments

2 Specific aspects of barrier island process understanding were identified as limiting. Experts had

3 confidence in estimating the probability of breaching or damage as a function of inundation, but

4 indicated there was considerably less scientific knowledge on which to base: (1) the relationship

5 of island width to breach formation; (2) the amounts of sand lost during breaching, lowering, or

6 narrowing of the berm; (3) the potential for minor breaches to self-heal versus developing into a

7 major breach; and (4) the relationship between upstream nourishment and resiliency of the berm

8 to storms. Although this uncertainty prompted a limited analysis of historic breach width that

9 was provided to aid technical experts with quantifying sand loss, the technical experts identified

10 a need for better understanding of all of these processes.

11 We also identified potential improvements in model implementation. Project phase was used as 12 the time step; in reality, repair decisions would be made immediately following each round of

13 damage. The cumulative cost of remobilizing equipment for multiple immediate repairs could

14 eventually tip the most cost-efficient solution toward waiting until the next phase, when the berm

15 would be built larger with higher resiliency. A more time-resolved DF could inform decisions

16 under those conditions. However, decreasing the time step would have increased the complexity

17 and computational expense to infeasible levels for the current project. Future applications will

18 have to consider the trade-offs between increasing model complexity to better resolve time-

19 dependent processes versus (1) added time in building the model and (2) reduction in the

20 intuitive transparency to stakeholders.

21 Similarly, the resolution of damage types and sand-loss volumes limited our ability to

22 comprehensively evaluate repair decisions for the full range of possible damage scenarios.

23 Experts provided probabilities of lowering (and narrowing) based on the minimum height (or

24 width) of the damaged berm over a discrete state of values. A storm will result in a longshore-

25 variant continuum of damages, but use of expert elicitation prohibited that level of complexity.

26 For example, one elicitation question asked experts to quantify the probability of major

27 breaching post-construction as a function of inundation, berm width, inclusion of fine-grain

28 sediment in repairs, and the presence of a breach at the end of construction. Even with

29 discretization and lack of longshore variability, technical experts had to provide probabilities for

3060 unique combinations for that question alone.

31 As an alternate to expert elicitation, the development and direct integration of statistical models

32 for physical processes into a DF would allow finer-scale discretization as well as more robust,

33 quantitative estimates of probabilities and uncertainties. The incorporation of inundation

34 probabilities in the Ship Island DF demonstrates the feasibility of this approach. In future efforts,

35 statistical models of barrier island dynamics (such as resiliency as a function of height, Plant et

36 al., 2014) could be integrated. Process-based statistical models without a formal decision-support 
framework have been considered for other applications such as groundwater systems (Fienen et al., 2013), endangered species (Gieder et al., 2014), and habitat evolution (Carruthers et al., 2013). Explicit integration of such models into formal decision support tools would allow consideration of a more complete range of scenarios and dependencies, such as multiple storm impacts and longshore variability of damage. Such a model could also inform decisions on prioritizing repairs under resource constraints (e.g., what combination of berm height and width is most resilient for a fixed quantity of available sand) that could not be considered here. In addition, objectivity in response would be reduced.

9 Lastly, the Ship Island exercise revealed where care must be taken in interpreting DF output. In many cases, repairing or not repairing damages did not result in a large shift in the expected performance. However, expected performance is an aggregate probability including the external driver of water levels. Extreme storms and associated high water levels are rare, and technical experts expressed uncertainty in quantifying the probability of damage as a function of berm condition should inundation occur. These two factors elevated the probability of positive outcomes for non-cost objectives regardless of damage, and muted the impact repairs have beyond their financial cost. Stakeholder objectives, however, may be conditional in ways that weren't captured in the model. For example, wave attenuation is most valuable during damaging, high-energy storm events. The probability of a storm happening is therefore potentially not as relevant as what protection the restoration project would provide should a storm occur. Additional analysis comprehensively evaluating the role of uncertainty on decisions and an investigation of better ways to identify and quantify conditional objectives was beyond the scope of this effort, but would improve the utility of DFs to restoration of dynamic systems.

\subsection{Regional and Long-Term Adaptive Management}

The use of DFs built through collaborative SDM could be expanded in coastal planning beyond the mid-construction application considered here. Physical numerical models were run during the design of the Ship Island project, but time and cost limitations prevented iterating through all possible construction templates and storm scenarios. A more efficient approach would be an iterative process where the uncertainties identified by the DF (such as the relationship between island width and berm resiliency) would guide numerical modeling and exploration of template parameter space, which subsequently could be used to reduce uncertainty in the DF. Similarly, DF-based identification of key parameters for assessing project success (in this case, evolving physical characteristics of the berm, wave heights in Mississippi Sound, etc.) could inform the design of an efficient monitoring plan and identification of take-action points in a longer-term adaptive management program (Lyons et al., 2008).

The Ship Island DFs also illustrate a mechanism for use in regional resource management. Barrier island resilience is tightly linked to sediment supply, which may come via longshore 
transport from upstream islands, terrestrial sources such as rivers, or anthropogenic nourishment, the source of which is often finite offshore sand resources. In addition, regional-scale resource management efforts do not have unlimited funds, and choices will arise as to where to focus efforts. The Ship Island application demonstrates that a DF developed through collaborative SDM provides a mechanism to balance potentially competing objectives while accounting for physical and financial interdependencies. This concept could be extended to consider multiple projects and inform regional-scale adaptive management. Other aforementioned benefits, such as informing project design and monitoring strategies, would then be reaped more broadly.

\section{Summary and Conclusions}

In the current project, collaborative structured decision-making (SDM) was applied to inform mid-construction decisions that may arise during closing of Camille Cut and restoration of the integrity of Ship Island in the northern Gulf of Mexico. Four phases of the project were considered: (B1) closure of the cut with a 5' high, 500' wide sand berm; (B2) increasing the height and width of the berm to 7' high, 1000' wide; (B3) capping the berm with fine-grain sand; and (E) nourishing East Ship Island to restore sea turtle habitat and maintain sediment supply. Due to the dynamic nature of barrier islands, the project might be damaged by storms prior to completion, necessitating decisions on how to respond.

Stakeholders and the decision-maker identified the project objectives, which included attenuating wave energy between the Gulf of Mexico and Mississippi Sound; avoiding increasing the flux of sediment into the Gulfport navigational channel; preserving salinity variation of Mississippi Sound; and increasing habitat for Gulf sturgeon, shore birds, and sea turtle nesting. Technical experts quantified the probabilities of potential storm damage, including the formation of a major or minor breach, lowering or narrowing of the berm, and loss of sand from East Ship Island. Two decision frameworks (DFs) were developed to quantify the impact of decisions to repair damages, made within the constraints of limited sand and money, on objectives. The first DF indicated sand was more limiting than funds and that major breaching would negatively impact objectives. The second DF addressed decisions to repair minor damages. For phases B1 and B2, cost was the primary factor because of the extremely low probability that sand would run out during those phases. Remobilizing equipment costs money, but reduces the risk of the berm incurring additional damage in its weakened state, which the DF indicated is ultimately more cost-effective for all but the most minor damages. For phase B3, we quantified the probability that major breaching would occur as a result of unrepaired damages and the incorporation of fine sand in repairs; what impacts that would have on objectives and cost-savings; and available sand as a limiting factor. If sand losses are relative minor, for example, the expected performance of repairing is lower than letting the damage remain due to the low risk of the weakened berm 
The Ship Island application is a prototype for using collaborative SDM in an adaptive management framework applied to restoration projects in dynamic environments such as barrier islands, where the system may change drastically as the project is underway. The effort identified how research in barrier island dynamics could be focused (volume of sand loss in breaching, narrowing, and lowering of a berm; impact of island width on breach probability) to better inform management, and illustrated the potential for direct incorporation of numerical model output or data to replace expert opinion. Finally, the project demonstrated how limited resources such as funding and sand can be explicitly accounted for in a DF to inform all phases of restoration projects (design, construction, monitoring, and adaptation), which could potentially be extended for regional barrier island restoration adaptive management.

We would like to thank the project team including Darin Lee, Nate Lovelace, and Ayse Karanci for their participation and expertise. We also want to thank Elise Irwin for her SDM expertise, including helping to facilitate the prototyping workshops and for her instrumental guidance and participation through the project. We are grateful to the respective agencies of the coauthors and the project participants (USACE, USGS, NPS, LA CPRA, Applied Coastal Inc.) in allocating the time for participants to engage in the effort, webinars and workshops, and to complete the project. We thank Alyssa Dausman for helping to identify and invite project participants and organizing the first workshop, and Holly Beck documenting the outcomes from the second stakeholder meeting. We also thank Linda Barnett for information regarding species habitat and for her review and Susan Rees for her feedback throughout the project. Thanks to Nathaniel environments. Funding was provided by the Department of the Interior Southeast Climate Science Center; however, the findings and conclusions in this article do not necessarily represent the views of the Southeast Climate Science Center. Any use of trade, firm, or product names is for descriptive purposes only and does not imply endorsement by the U.S. Government.

\section{References}

Blomquist, S.M., Johnson, T.D., Smith, D.R., Call, G.P., Miller, B.N., Thurman, W.M., McFadden, J.E., Parkin, M.J., Boomer, G.S., 2010. Structured decision-making and rapid prototyping to plan a management response to an invasive species. J. Fish Wildlife Mgmt., 1(1), 18-32. 
Byrnes, M.R., Rosati, J.D., Griffee, S.F., Berlinghoff, J.L., 2012. Littoral sediment budget for the Mississippi Sound barrier islands. Technical Report ERDC/CHL TR-12-9, U.S. Army Engineer Research and Development Center, Vicksburg, MS.

Byrnes, M.R., Rosati, J.D., Griffee, S.F., Berlinghoff, J.L., 2013. Historical sediment transport pathways and quantities for determining an operational sediment budget: Mississippi Sound barrier islands, in: Brock, J.C., Barras, J.A., Williams, S.J. (Eds.), Understanding and Predicting Change in the Coastal Ecosystem of the Northern Gulf of Mexico, J. Coast. Res., Special Issue No. 63, pp. 166-183.

Byrnes, M.R., McBride, R.A., Penland, S., Hiland, M.W., Westphal, K.A., 1991. Historical changes in shoreline position along the Mississippi Sound barrier islands, in: Coastal Depositional Systems in the Gulf of Mexico: Quaternary Framework and Environmental Issues, GCS-SEPM 12th Annual Research Conference, pp. 43-55.

Carruthers, T.J.B., Beckert, K., Schupp, C.A., Saxby, T., Kumer, J.P., Thomas, J., Sturgis, B., Dennison, W.C., Williams, M., Fisher, T., Zimmerman, C.S., 2013. Improving management of a mid-Atlantic coastal barrier island through assessment of habitat condition. Est. Coast. Shelf Sci. 116, 74-86.

Claudino-Sales, V., Wang, P., Horwitz, M.H., 2008. Factors controlling the survival of coastal dunes during multiple hurricane impacts in 2004 and 2005: Santa Rose barrier island, Florida. Geomorphology 95(3-4), 295-315.

Dalkey, N., 1969. An experimental study of group opinion: the Delphi method. Futures 1(5), 480-426.

Feagin, R.A., Smith, W.K., Psuty, N.P., Young, D.R., Martinez, M. L., Carter, G.A., Lucas, K.L., Gibeaut, J.C., Gemma, J.N., Koske, R.E., 2010. Barrier islands: Coupling anthropogenic stability with ecological sustainability. J. Coast. Res. 26(6), 987-992.

Fienen, M.N., Masterson, J.P., Plant, N.G., Gutierrez, B.T., Thieler, E.R., 2013. Bridging groundwater models and decision support with a Bayesian network. Water Resources Res. 49(10), 6459-6473.

Foxworth, R.D., Priddy, R.R., Johnson, W.B., Moore, W.S., 1962. Heavy minerals of sand from recent beaches of the Gulf Coast of Mississippi and associated islands. Mississippi Geological Survey, Bulletin 93.

Gieder, K.D., Karpanty, S.M., Fraser, J.D., Catlin, D.H., Gutierrez, B.T., Plant, N.G., Turecek, A.M., Theiler E.R, 2014. A Bayesian network approach to predicting nest presence of the 
federally-threatened piping plover (Charadrius melodus) using barrier island features. Eco. Model. 276, 38-50.

Gregory, R., Failing, L., Harstone, M., Long, G., McDaniels, T., Ohlson, D., 2012. Structured decision making: a practical guide to environmental management choices. John Wiley \& Sons, West Sussex.

Gregory, R., Long, G., 2009. Using structured decision making to help implement a precautionary approach to endangered species management. Risk Analysis 29(4), 518532.

Hammond, J.S., Keeney, R.L., Raiffa, H., 1999. Smart Choices: A Practical Guide to Making Better Life Decisions. Broadway Books, New York.

Houser, C., Hapke, C., Hamilton, S., 2008. Controls on coastal dune morphology, shoreline erosion and barrier island response to extreme storms. Geomorphology 100(3-4), 223240.

Howard, R. 1988. Decision Analysis: Practice and Promise. Manage. Sci. 34 (6), 679-695.

Knowles, S.C., Rosati, J.D., 1989. Geomorphic and coastal process analysis for ship channel planning at Ship Island, Mississippi. U.S. Army Corps of Engineers, Technical Report CERC-89-1.

Komar, Paul. 1988. Beach Processes and Sedimentation. Prentice-Hall, New Jersey.

Kuhnert, P.M., Martin, T.G., Griffiths, S.P., 2010. A guide to eliciting and using expert knowledge in Bayesian ecological models. Eco. Letters 13(7), 900-914.

Lyons, J. E., Runge, M.C., Laskowski, H.P., Kendall, W.L., 2008. Monitoring in the Context of Structured Decision-Making and Adaptive Management. J. Wildlife Manage. 72(8), 1683-1692.

Morton, R.A., 2007. Historical changes in the Mississippi-Alabama barrier island chain and the roles of extreme storms. U.S. Geological Survey Open-File Report 2007-1161.

Morton, R.A., 2008. Historical changes in the Mississippi-Alabama barrier island chain and the roles of extreme storms. J. Coast. Res. 24(6), 1587-1600.

Neckles, H.A., Lyons, J.E., Guntenspergen, G.R., Shriver, W.G., Adamowicz, S.C., 2015. Use of structured decision making to identify monitoring variables and management priorities for salt march ecosystems. Estuaries and Coasts 38(3), 1215-1232. 
Nichols, J. D., Koneff, M. D., Heglund, P. J., Knutson, M. G., Seamans, M. E., Lyons, J. E., Morton, J. M., Jones, M. T., Boomer, G. S., Williams, B.K., 2011. Climate change, uncertainty, and natural resource management. J. Wildlife Manage. 75, 6-18.

Otvos, E.G., Carter, G.A., 2008. Hurricane Degradation - Barrier Development Cycles, Northeastern Gulf of Mexico: Landform Evolution and Island Chain History. J. Coast. Res. 24(2), 463-478.

Penland, S., Boyd, R., 1981. Shoreline changes on the Louisiana barrier coast. Oceans (81), 209219.

Runge, M. C., Cochrane, J. F., Converse, S. J., Szymanski, J. A., Smith, D. R., Lyons, J. E., Eaton, M. J., Matz, A., Barrett, P., Nichols, J. D., Parkin, M.J., 2011a. An overview of structured decision making, revised edition. U.S. Fish and Wildlife Service, National Conservation Training Center, Shepherdstown, West Virginia, USA.

Runge, M.C., Converse, S.J., Lyons, J.E., 2011b. Which uncertainty? Using expert elicitation and expected value of information to design an adaptive program. Bio. Cons. 144(4), 1214-1223.

Sallenger Jr., A. H., 2000. Storm impact scale for barrier islands. J. Coast. Res. 16(3), 890-895.

Sallenger, A.H., Wright, C.W., Lillycrop, J., Howd, P., Stockdon, H., Guy, K.K., Morgan, K., 2006. Extreme changes to barrier islands along the central Gulf of Mexico coast during Hurricane Katrina, in: Farris, G.S., Smith, G.J., Crane, M.P., Demas, C.R., Robbins, L.L., Lavoie, D.L. (Eds.), Science and the storms: the USGS response to the hurricanes of 2005, USGS Circular 1306, pp. 113-118.

Soulsby, R., 1997. Dynamics of marine sands. Thomas Telford Publications, London.

Stockdon, H.F., Fauver, L.A., Sallenger, A.H., Wright, C.W., 2006. Impacts of Hurricane Rita on the Beaches of Western Louisiana, in: Farris, G.S., Smith, G.J., Crane, M.P., Demas, C.R., Robbins, L.L., Lavoie, D.L. (Eds.), Science and the storms: the USGS response to the hurricanes of 2005, USGS Circular 1306, pp. 119-123.

Stutz, M.L., Pilkey, O.H., 2011. Open-ocean barrier islands: Global influence of climactic, oceanographic, and depositional settings. J. Coast. Res. 27(2), 207-222.

Thorne, K. M., Mattsson, B. J., Takekawa, J., Cummings, J., Crouse, D., Block, G., Bloom, V., Gerhart, M., Goldbeck, S., Huning, B., Sloop, C., Stewart, M., Taylor, K., Valoppi, L., 2015. Collaborative decision-analytic framework to maximize resilience of tidal marshes to climate change. Ecology and Society 20(1), 30. 
1 U.S. Army Corps of Engineers (USACE), 2009. Mississippi Coastal Improvements Program (MsCIP), Comprehensive Barrier Island Restoration Hancock, Harrison, and Jackson

U.S. Fish and Wildlife Service (USFWS), 2015. Biological Opinion. Mississippi Coastal

Wamsley, T.V., Godsey, E.S., Bunch, B.W., Chapman, R.S., Gravens, M.B., Grzegorzewski, A.S., Johnson, B.D., King, D.B., Permenter, R.L., Tillman, D.H., Tubman, M.W., 2013. Mississippi Coastal Improvements Program; Evaluation of Barrier Island Restoration Efforts. U.S. Army Corps of Engineers, Engineering Research and Development Center, ERDC TR-13-12. 
1 Fig. 1 Mississippi Barrier Island System. From west to east, the islands are Cat Island, West Ship

2 Island, East Ship Island, Horn Island, Petit Bois Island, and Dauphin Island. Images from Google

3 Earth@.

4 Fig. 2 Influence diagram for decision framework 1. Arrows indicate connectivity between 5 elements, some of which (such as a major breach) may or may not occur. Each element is a

6 function of all others that point to it; for example, a major breach at the end of Phase B2 is a

7 function of the occurrence of a major breach during phase B2 and the decision to repair it.

8 External drivers (brown) are in italics with dashed arrows; decision node (green) is a thick box

9 with thick arrow; and ultimate objectives (red) are in dashed boxes, a cluster of which are related

10 to the ecological integrity of the beach and Mississippi Sound. Expert elicitation used for

11 underlined nodes. The decision to repair a major breach in phase B1 is automatic, but influences

12 the budget and available sand (in blue).

13 Fig. 3 Portion of the influence diagram for decision framework 2 for phases B1and B2. Arrows

14 indicate connectivity between elements, some of which (such as berm damage) may or may not

15 occur. Each element is a function of all others that point to it; for example, the fill condition at

16 the end of Phase B2 is a function of the narrowing, lowering, or major breaching during Phase

17 B2, along with decisions to repair that damage. External drivers (brown) in italics with dashed

18 arrows, and decision node (green) in thick box with thick arrow. The only ultimate objective (red

19 dashed box) impacted during phases B1 and B2 is cost savings through decisions to repair

20 damage (linkage indicated by “\$”). Expert elicitation was used for underlined nodes. "Available

21 sand (in blue) and fill condition at the end of phase B2 connects this diagram to subsequent

22 phases B3 and E (Fig. 4).

23 Fig. 4. Portion of the influence diagram for decision frameowkr 2 for phases B3and E. Arrows

24 indicate connectivity between elements, some of which (such as berm damage) may or may not

25 occur. Each element is a function of all others that point to it; for example, the fill condition at

26 the end of Phase B3 is a function of the narrowing, lowering, or major breaching during Phase

27 B3, along with decisions to repair that damage. External drivers (brown) in italics with dashed

28 arrows, and decision nodes (green) in thick boxes with thick arrows. Cost savings depends

29 (linkage indicated by "\$”) on repair decisions, while the remaining ultimate objectives (red

30 dashed boxes) are impacted by the condition of the project post-construction "\$". Expert

31 elicitation used for underlined nodes. ${ }^{a}$ Available sand (in blue) and fill condition at the end of

32 phase B2 connects this diagram to prior phases B1 and B2 (Fig. 3).

33 Fig. 5 Simplified berm profile used in estimate of sand volume lost as a result of damages

34 including berm narrowing, lowering, and a breach forming. Pre-damage correlates to the berm is

35 in its "Original" state (left side), and post-damage to the berm in its "New" state (right side).

36 This profile does not account for berm curvature at the toe, crest, or along the sides. Shown are 
1 all possible forms of damage (breach, lowering, narrowing); however, probability and sand loss

2 volumes for each of these processes were elicited and calculated individually.

3 Fig. 6. Value of sand loss associated with (A) narrowing and (B) lowering of the berm behind

4 construction in phase B3. Individual technical experts estimated the minimum, expected, and

5 maximum sand loss; shown are the average of those values. Major breach sand loss (dashed line)

6 was arrived at via open consensus. (C) Probability of water levels exceeding berm height in the

7 10-years post construction. (D) Probability of a major breach post-construction as a function of

8 berm width, assuming a berm height of 7'. Values in the general case incorporate the probability

9 of inundation, whereas with (without) inundation gives the probabilities assuming inundation

10 does (does not) occur.

11 Fig. 7. (A) Predicted ultimate objective outcomes depending on whether or not a major breach of 12 the Camille Cut berm that occurs during construction is repaired (from first decision model). (B)

13 Predicted ultimate objective outcomes depending on whether or not a major breach of the

14 Camille Cut berm occurs post-construction. (from second decision model).

15 Fig. 8. Predicted outcomes for non-cost savings ultimate objectives based on scenarios for minor 16 damages to the Camille Cut berm and potential repairs at the end of phase B3. More-extensive 17 scenario: narrowed to 1-200' longshore width, lowered to $<4$ ' height; Less-extensive scenario:

18 narrowed to 351-500' longshore width, lowered to 6' elevation. 


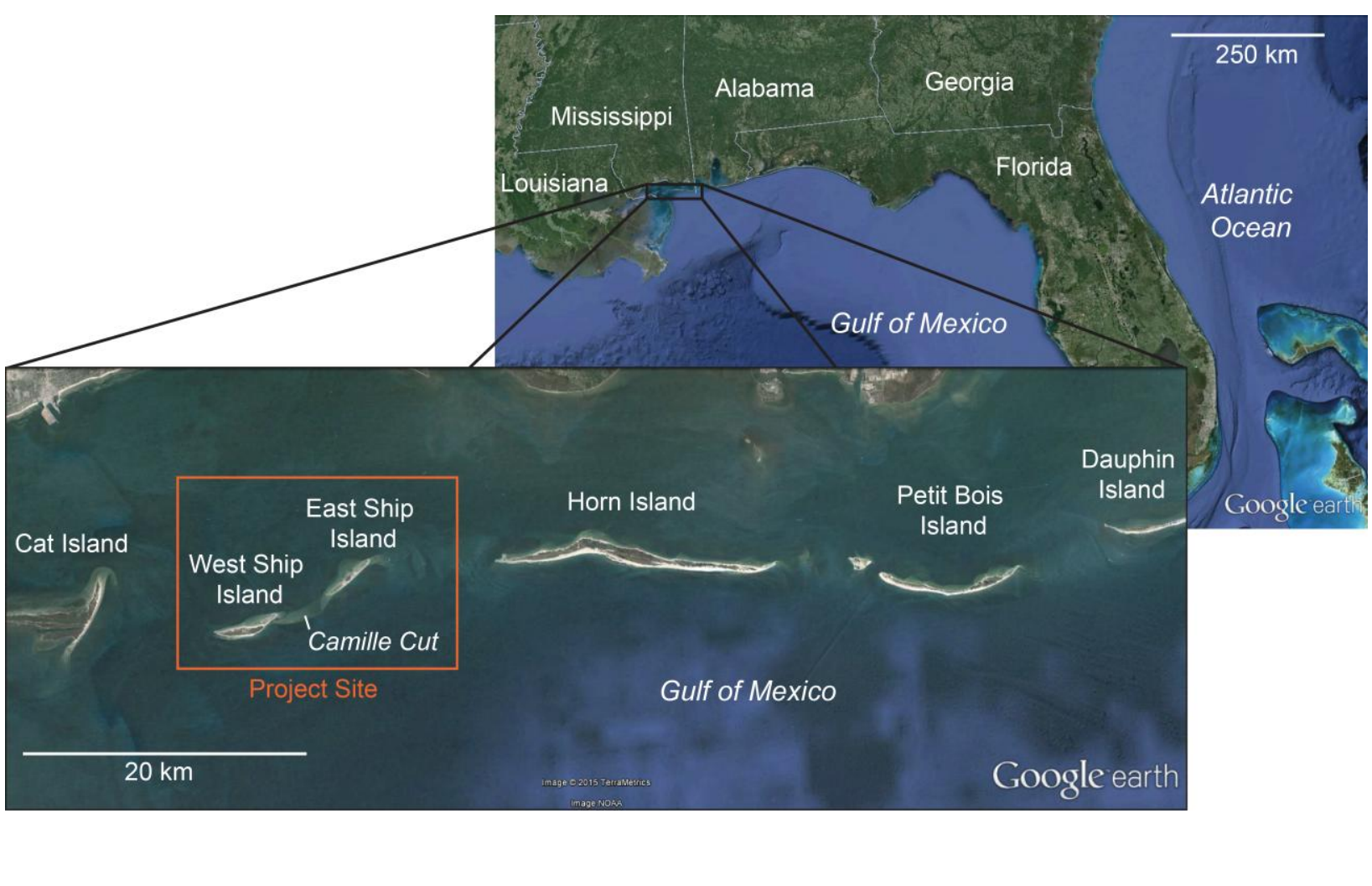




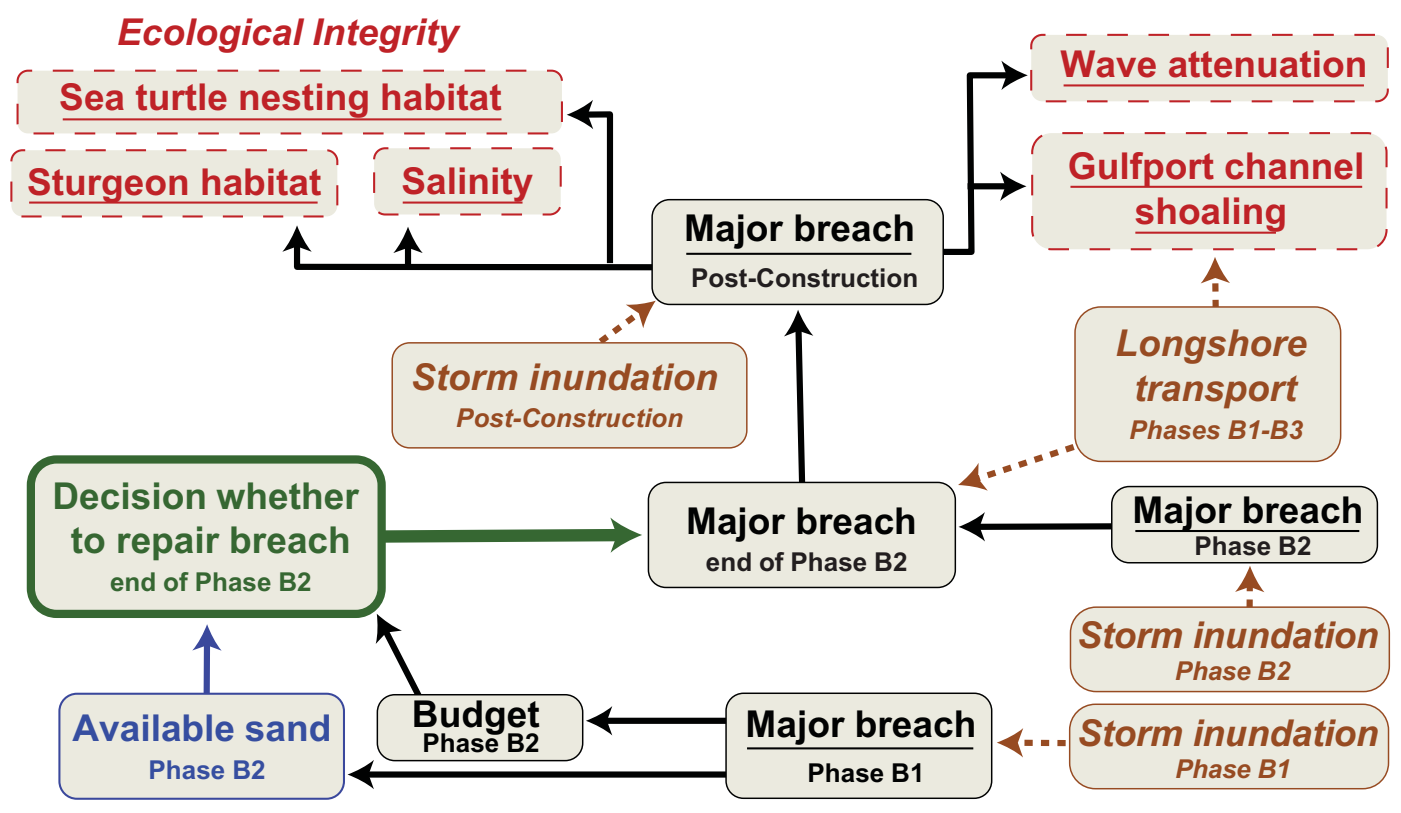




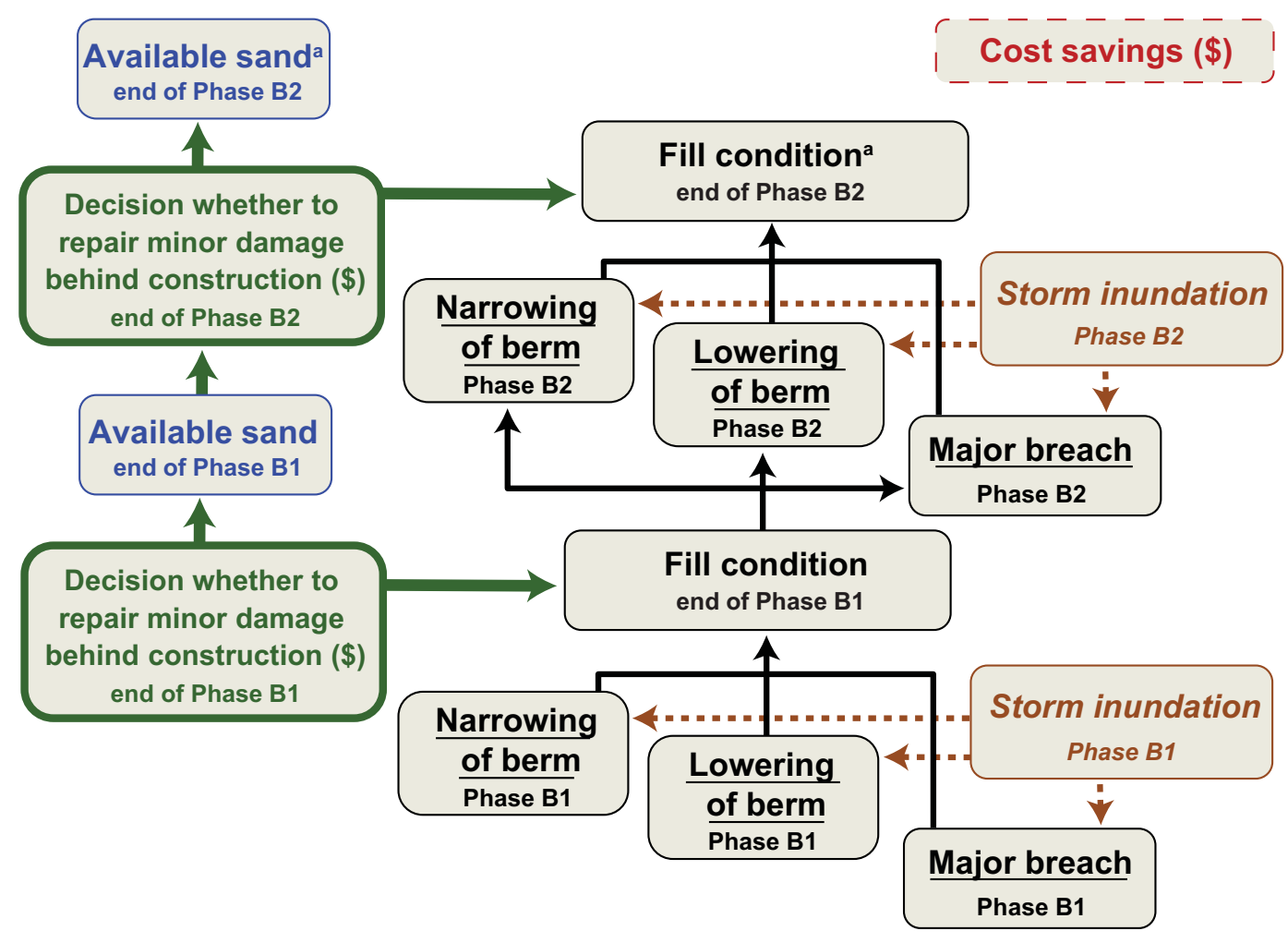




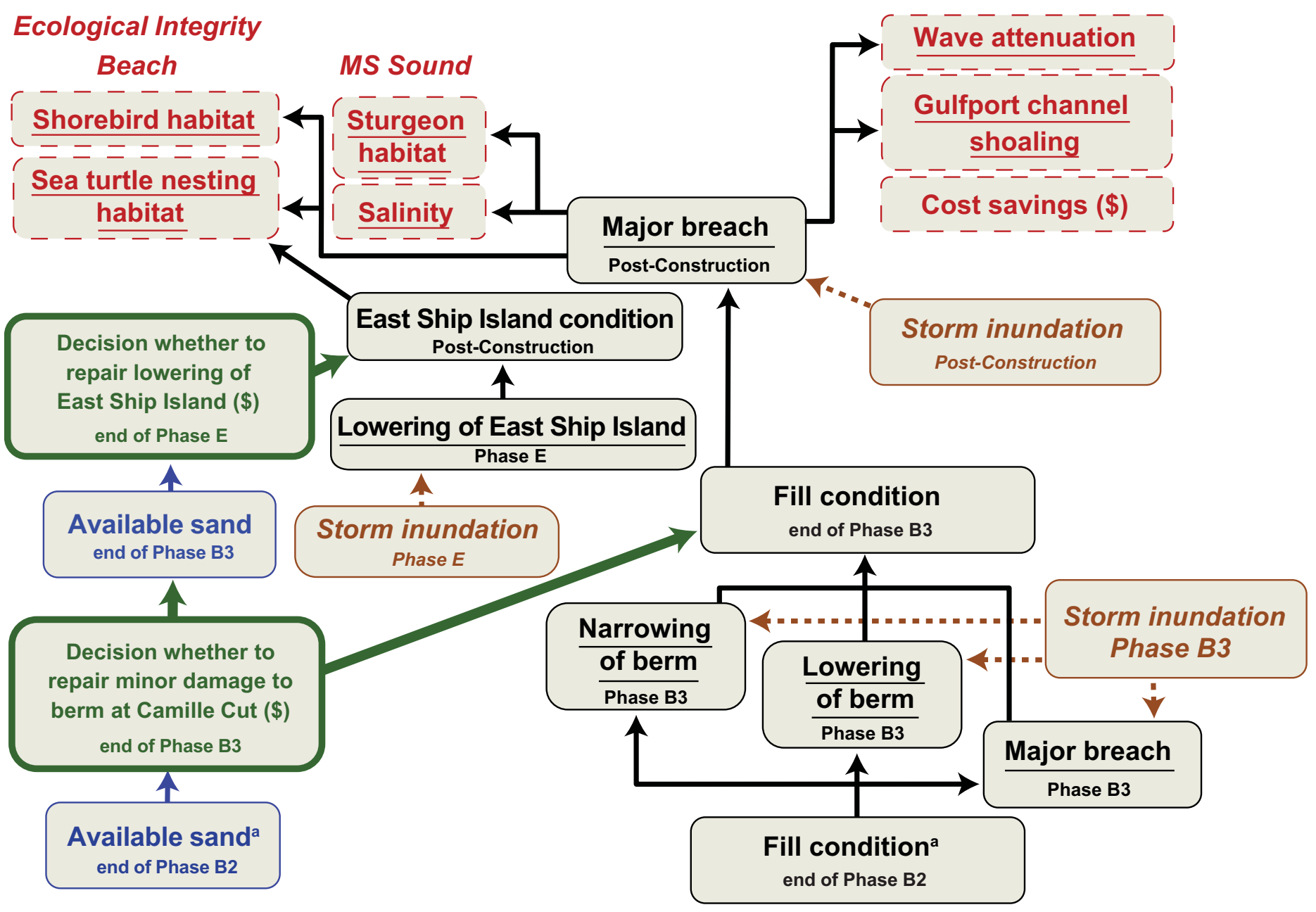



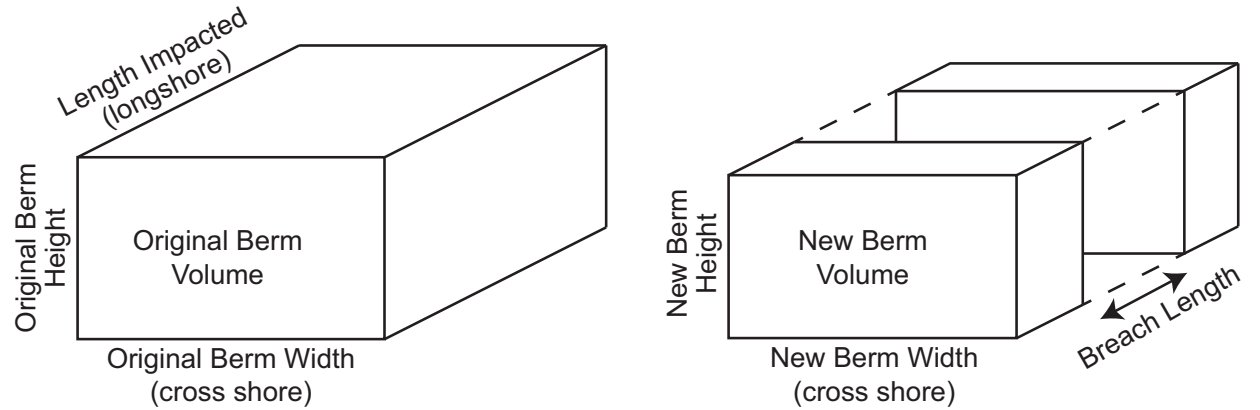

Sand Loss = Original Volume - New Volume

(Effected Length * Original Width * Original Height) - ((Effected Length - Breach Length)*New Width *New Height) 

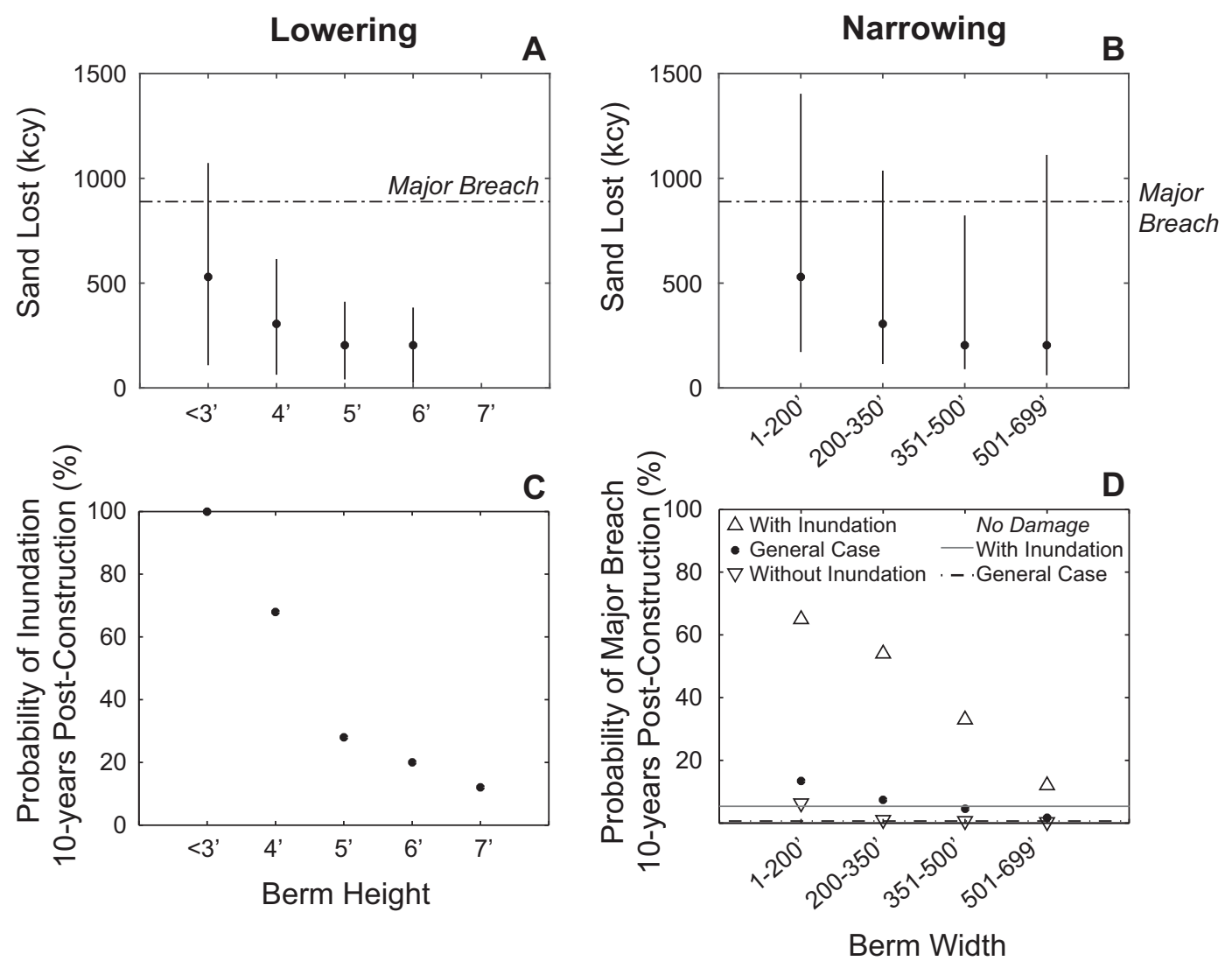


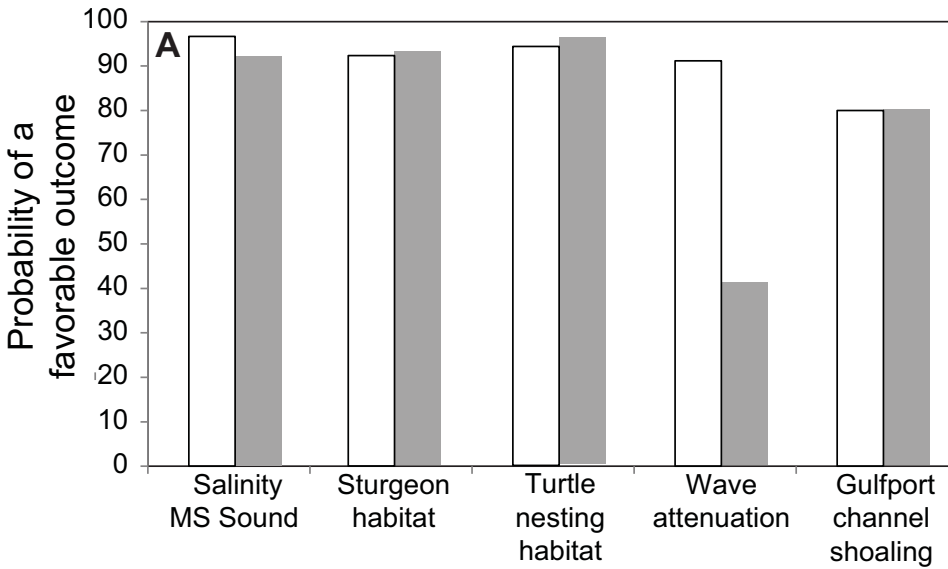

Unrepaired major breach

during phase $\mathrm{B2}$

$\square$ No

Yes

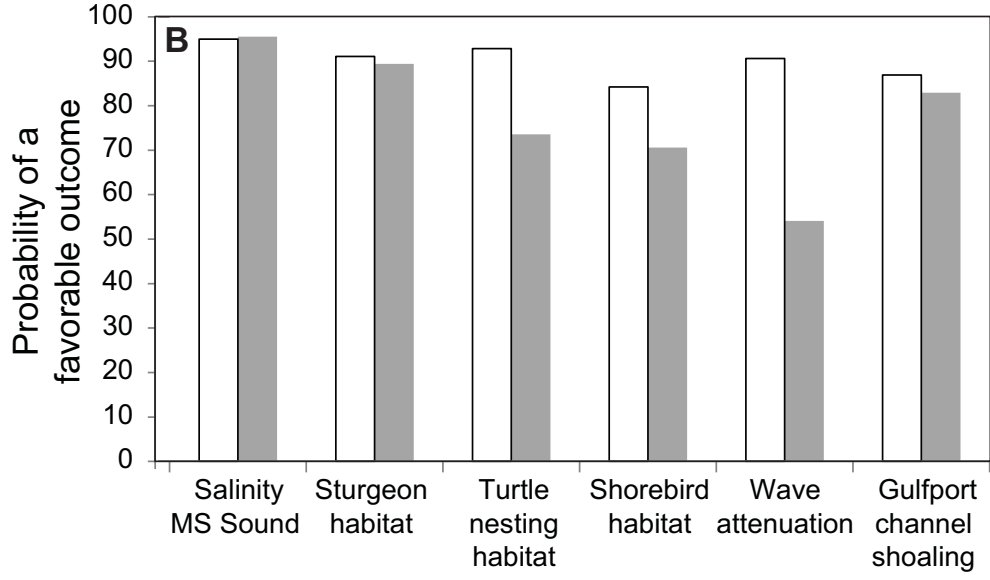

Occurrence of major breach post-construction

$\square$ No

Yes

Ultimate objective 


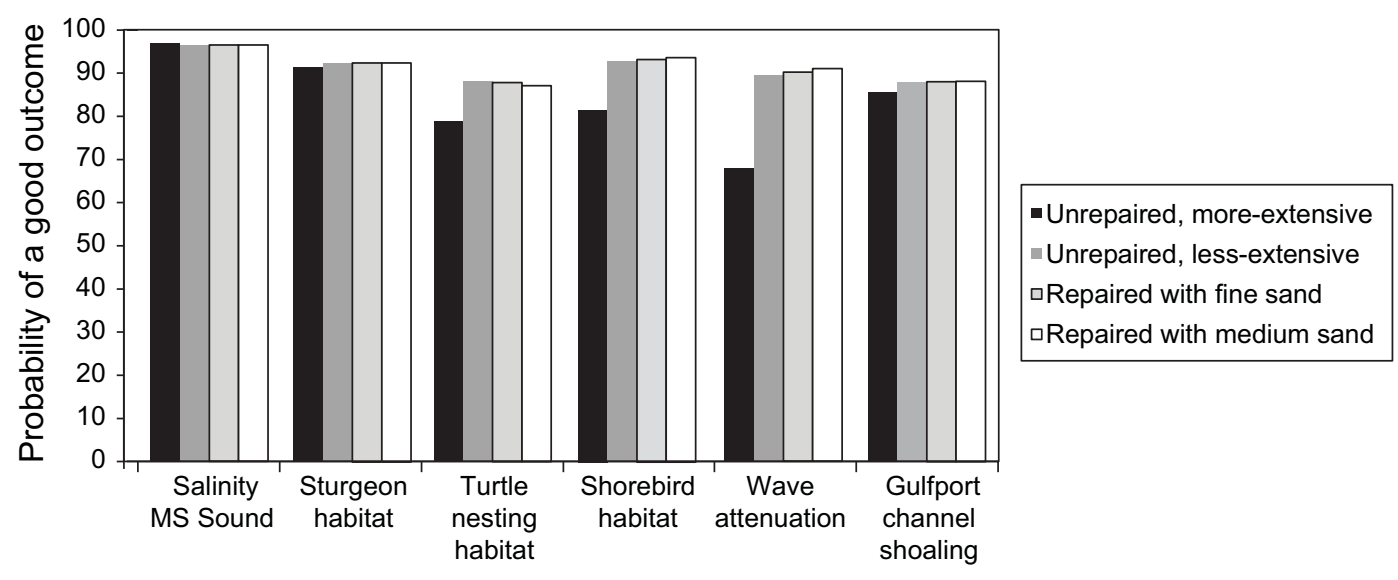

